\title{
Choledochocele: A Case Report and Discussion of Diagnosis Criteria
}

\author{
Linlin Zhu ${ }^{1}$ Zhibao Lv$^{1}$ jiangbin Liu ${ }^{1}$ Weijue $\mathrm{Xu}^{1}$ \\ ${ }^{1}$ Department of Surgery, Children's Hospital of Shanghai Jiaotong \\ University, Shanghai, China \\ Eur J Pediatr Surg Rep 2015;3:85-89. \\ Address for correspondence Zhibao Lv, PhD, Department of Surgery, \\ Children's Hospital of Shanghai Jiaotong University, No. 355 Luding \\ Road, Putuo District of Shanghai, Shanghai 200060, China \\ (e-mail: Ivzhibao@sohu.com).
}

\begin{abstract}
Keywords

- choledochocele

- duodenal duplication

- radiologic criteria

A 6-year-old girl presented with intermittent abdominal pain, without jaundice and a palpable mass in the epigastrium. Preoperative imaging and upper endoscopy suggested duodenal duplication. During surgery, the patient was diagnosed with a rare type of choledochal cyst-choledochocele (type 3b). The authors emphasize that, in children, choledochocele should be included in the differential diagnosis of cystic lesions located in the duodenal area and the head of the pancreas area, regardless of jaundice or abnormal liver function. Since mucosal histology showing duodenal mucosa did not match the final diagnosis, we suggest that three criteria should be met for the diagnosis of a choledochocele to be diagnosed: (1) a cyst protruding into the duodenal lumen; (2) filling with contrast during cholangiography and (3) a filling defect on X-ray barium meal.
\end{abstract}

\section{New Insights and the Importance for the Pediatric Surgeon}

This article reports a rare type of choledochal cyst-choledochocele, and tell the diagnosis criteria. Cholangiography is very important to distinguish choledochocele and duodenal duplication.

\section{Introduction}

A choledochocele is a cystic dilation of the distal common bile duct (CBD). It corresponds to a type 3 choledochal cyst in the classification by Todani et $\mathrm{al}^{1}$ and is extremely rare. ${ }^{2}$ The diagnosis is challenging and rarely made before surgery, as the presenting symptoms vary wildly and are nonspecific. Besides, the radiological findings of choledochocele and duodenal duplication cyst are very similar. We present a case of a 6-year-old girl with this rare disease entity.

\section{Case Report}

A 6-year-old girl was admitted to a local hospital for acute abdominal pain associated with vomiting and fever. Although her symptoms disappeared quickly with anti-infectious ther-

received

March 26, 2015

accepted after revision

July 3, 2015

published online

September 9, 2015 apy, she had repeated episodes of abdominal pain frequently in the following year; the pain lasted for several minutes and alleviated spontaneously. At that time, she showed no other symptoms, and her physical examination and serum chemistry levels were normal. There was no other significant medical history, and the family history was not pertinent.

On physical examination, a nontender $(5 \mathrm{~cm} \times 4 \mathrm{~cm})$ firm mass with a smooth surface was palpable in the epigastric region. The mass was nonmobile and dull to percussion. The mass did not have a bruit on auscultation. There was no hepatomegaly or splenomegaly.

The child was admitted, and the investigations obtained at our institution were as follows.

Liver function tests were normal. A magnetic resonance cholangiopancreatography (MRCP) scan revealed a cyst $(4 \mathrm{~cm} \times 2.6 \mathrm{~cm} \times 6 \mathrm{~cm})$ on the right of the head of the
License terms

Stuttgart · New York

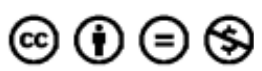




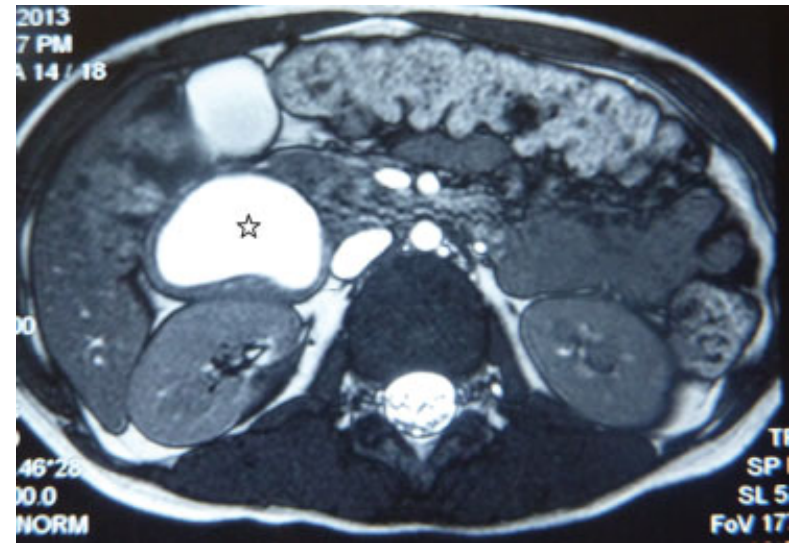

Fig. 1 MRCP scan revealed a cyst $(\star, 3.99 \mathrm{~cm} \times 2.58 \mathrm{~cm} \times 5.99 \mathrm{~cm})$ on the right of the head of the pancreas with possible interaction with the descending duodenum.

pancreas with possible interaction with the descending duodenum (-Fig. 1). On upper gastrointestinal X-ray barium meal, a filling defect was noted on the duodenal descending part (-Fig. 2). Endoscopic gastroduodenoscopy showed mucosal bulging at the duodenal descending part (-Fig. 3). In addition, superficial gastritis was detected. A provisional diagnosis of duodenal duplication was made.

Laparoscopy was performed and a dilated duodenal descending part was found, so we considered the mass was in the lumen of duodenum. A cholangiogram was done intraoperatively (through the gall bladder), and showed that the distal CBD was dilated and protruded into the duodenal lumen (-Fig. 4), consistent with a choledochocele. Then we turned to laparotomy. The duodenum was opened, and duodenal papilla was found within the cyst wall (-Fig. 5). We opened the cyst and once more performed a cholangio-

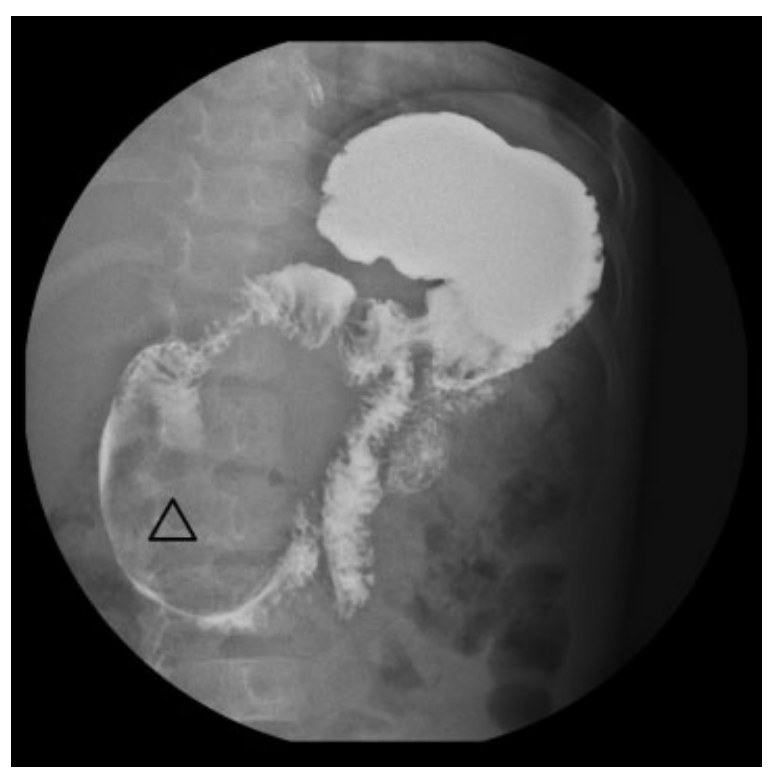

Fig. 2 Upper gastrointestinal X-ray barium meal found filling defect of duodenal descending part $(\Delta)$.

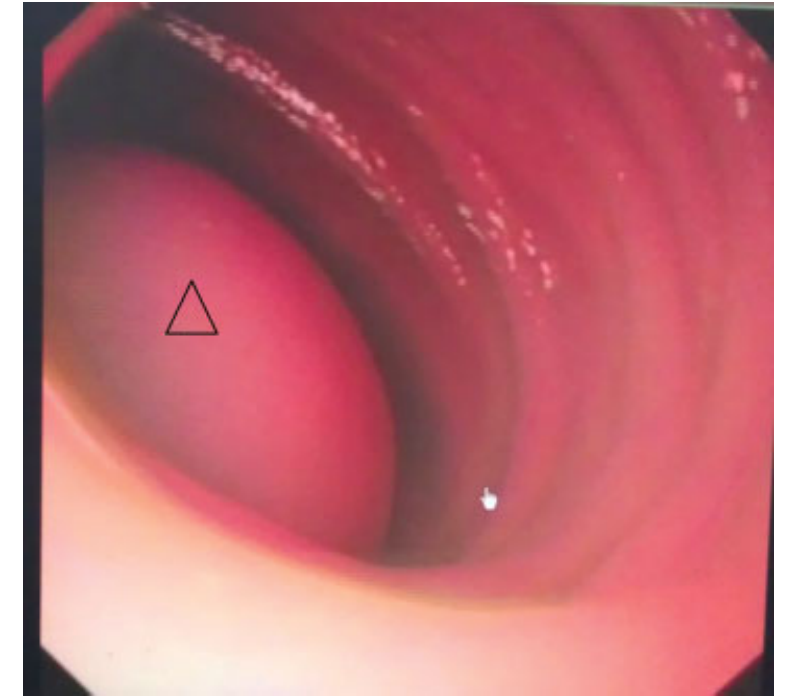

Fig. 3 Endoscopic gastroduodenoscopy found a mucosal bulging at the duodenal descending part $(\Delta)$.

gram (through the tiny opening in the cyst and the orifice of the duodenal papilla); a confirmed diagnosis of choledochocele (type B) was made, and cystotomy and unroofing of the

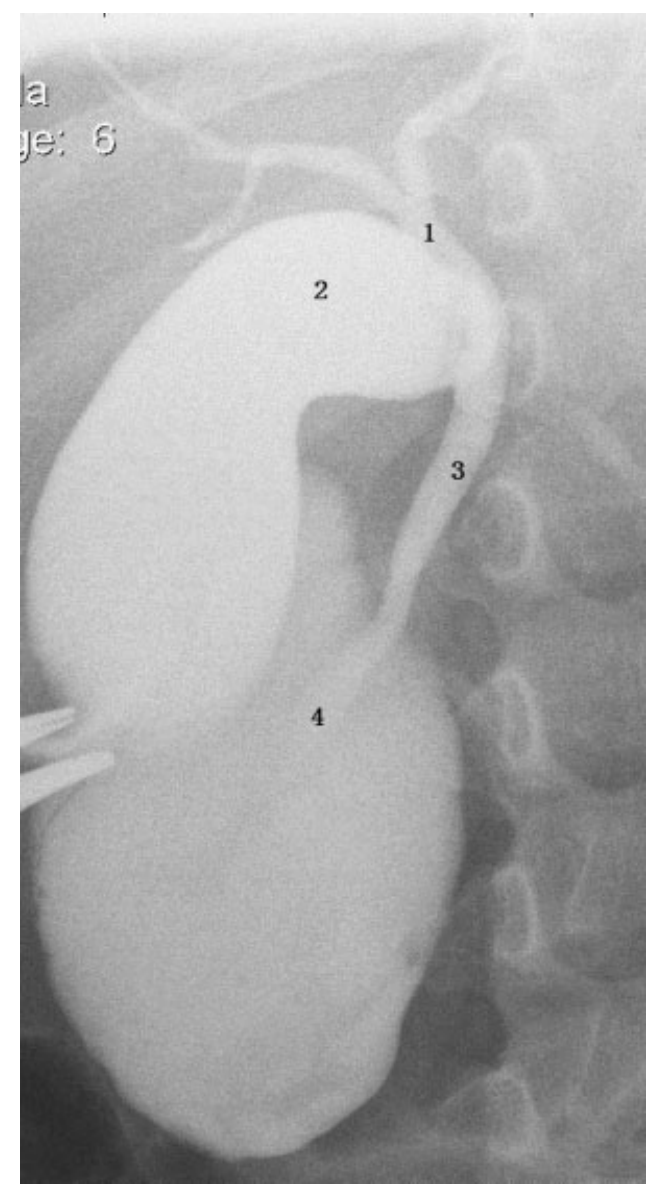

Fig. 4 Cholangiogram done intraoperatively (through the gall bladder) showed that the distal common bile duct was dilated and protruded into the duodenal lumen (4). (1) common hepatic duct; (2) gallbladder; (3) common bile duct. 

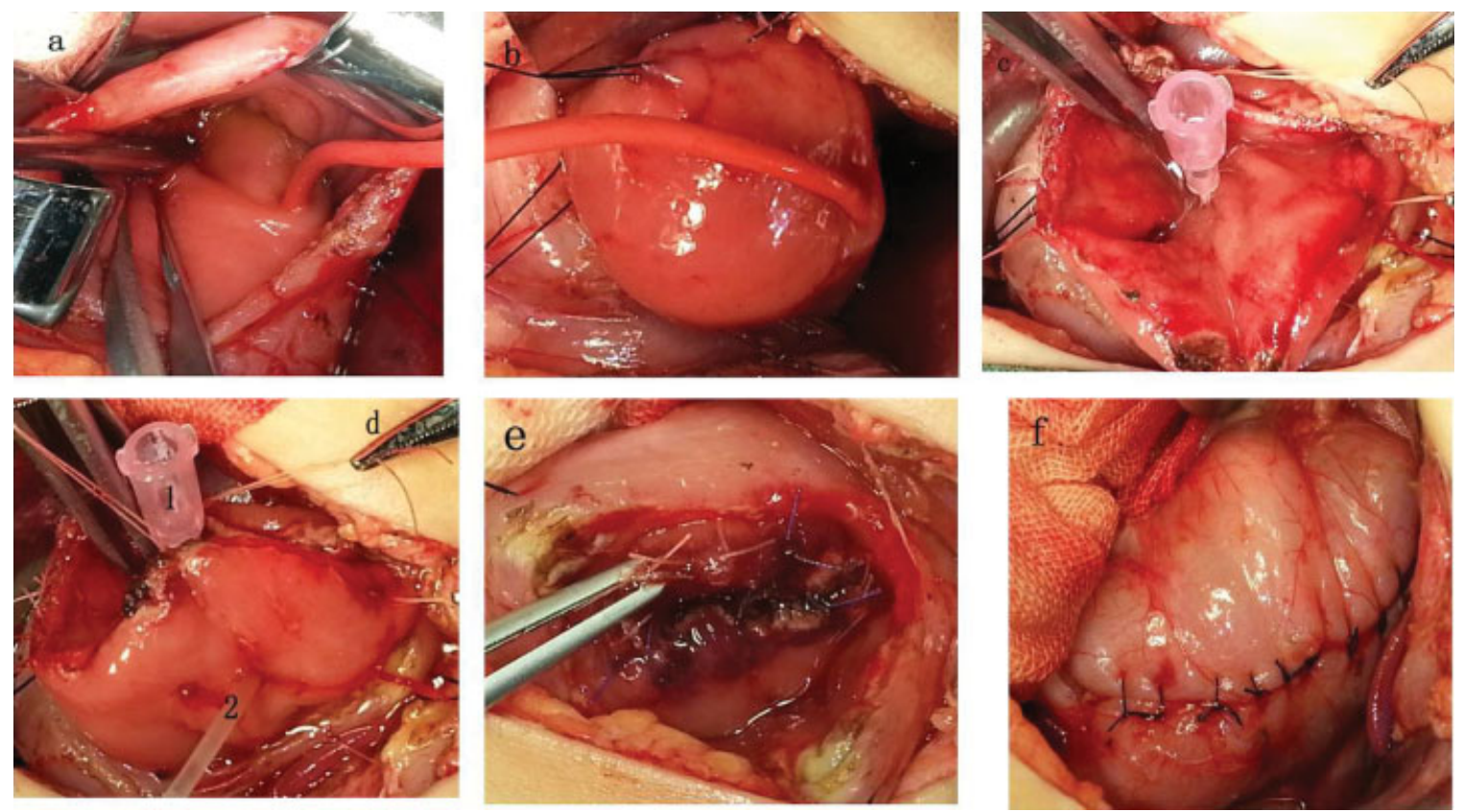

Fig. 5 Intraoperative images demonstrated excision of the choledochocele. (a) The cyst wall visible through the lateral duodenotomy; (b) the cyst abutting the cannulated ampulla of Vater; (c) the cyst opened, a tiny opening found in the cyst (cannulated); (d) The tiny opening in the cyst (1) was the orifice of the pancreatic duct; duodenal papilla (2); (e) fenestration of the cyst; and (f) the closed duodenotomy.

cyst wall and suturing to the edges of the cyst were performed (-Fig. 6).

A pathologic examination of the specimen showed untypical duodenal mucosa (mucous gland with goblet cells) and smooth muscle layer under mucosa, but without a definite brush border ( - Fig. 7). Nonatypical cells were detected.

A follow-up color Doppler ultrasonography was performed 6 months after surgery, which was normal. The patient had an uneventful clinical course for 1 year after the surgery.

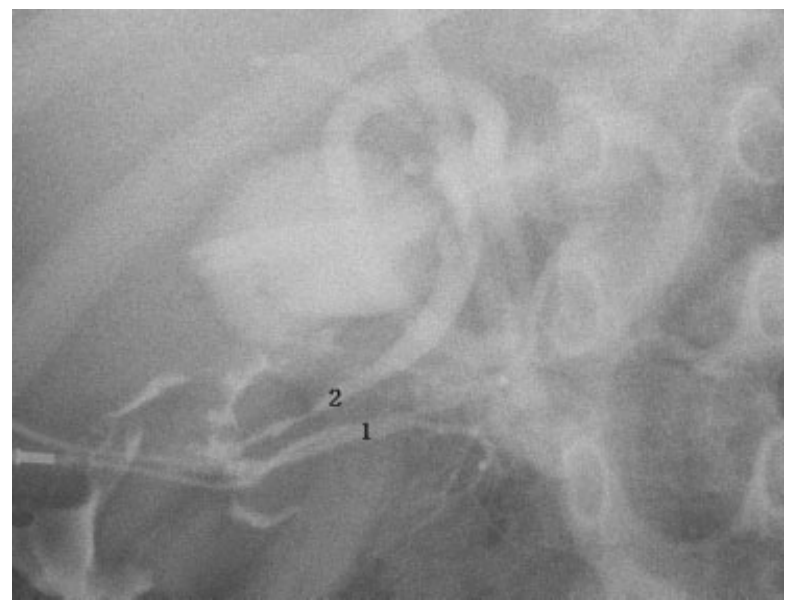

Fig. 6 The cholangiogram through the opening in the cyst showed normal pancreatic duct (1) and bile duct (2).

\section{Discussion}

A choledochocele is a cystic dilation of the distal CBD and the third subtype of biliary cysts in the classification by Todani et al. ${ }^{1}$ It is a rare entity, and only $1.4 \%$ of all congenital biliary dilation patients have choledochoceles. ${ }^{2}$ Duodenal duplication cyst is also extremely rare. It represents only 2 to $12 \%$ of digestive tract duplications $^{3-8}$ and has an estimated prevalence of less than 1 per 100,000 live births. ${ }^{5,9}$ They have very similar clinical features: abdominal pain, nausea/vomiting, pancreatitis, cholestasis/jaundice, and cyst infection. The MRCP finding of both choledochocele and duodenal duplication cyst is that a cyst protrudes inside the duodenum lumen. It may sometimes be difficult to distinguish choledochocele from duodenal duplication on clinical features and routine imaging studies. ${ }^{10}$

A choledochocele is defined by its relationship to the bile duct, whereas duodenal duplication is defined by its relationship to the duodenum. Sarris and Tsang ${ }^{11}$ proposed a classification of choledochocele into type $\mathrm{A}$ (further subclassified as $\mathrm{A} 1, \mathrm{~A} 2$, and A3) and type B. Type A1 has a common opening of the pancreatic duct (PD) and CBD into the cyst. In type $A 2$, there are separate openings of the PD and CBD. Type A3 is similar to $\mathrm{A} 2$, but the cyst is small and intramural. In type $\mathrm{B}$ choledochocele, the ampulla empties directly into the duodenum and the cyst represents a diverticulum of the distal CBD protruding into the duodenal lumen. Duplications may occur throughout the alimentary tract. They typically arise from the mesenteric border of the gut, share a common wall with the intestine, and may or may not communicate with the gut lumen. According to these anatomic features, radiologic criteria differentiating choledochoceles from duodenal duplications have been proposed based on cholangiography and 

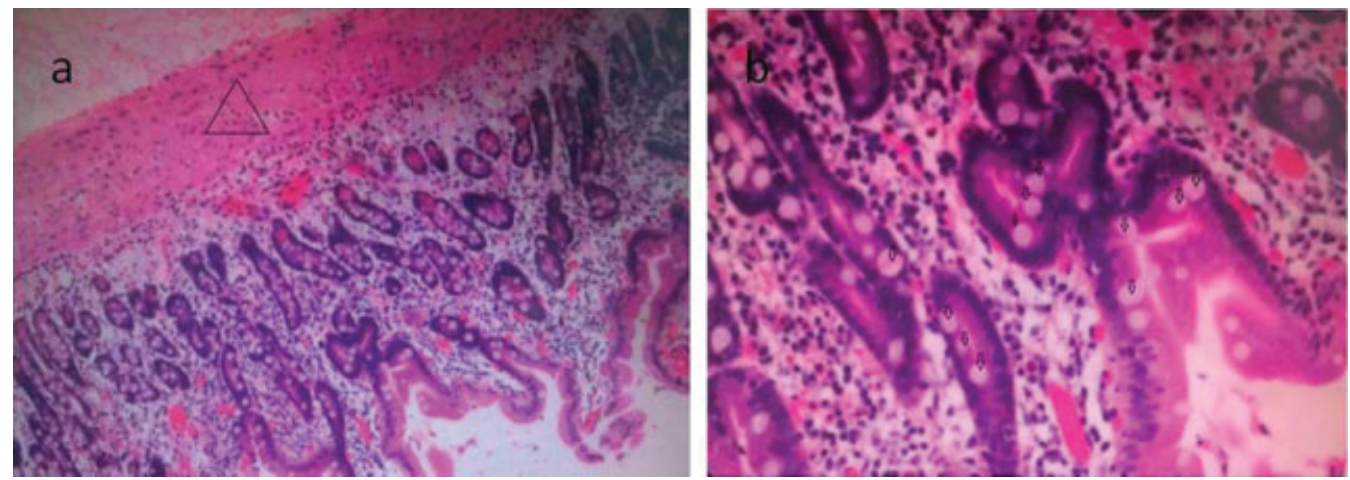

Fig. 7 Choledochocele. (a) Untypical duodenal mucosa with smooth muscle layer $(\Delta)$. (b) Mucous gland with goblet cells ( $\downarrow$ ).

upper gastrointestinal barium studies. By using these criteria, choledochoceles fill with contrast during cholangiography but not during barium studies, whereas the lack of filling during both studies along with the absence of bile content within the cyst defines duodenal duplications. ${ }^{12}$ In this case, an intraluminal duodenal filling defect on barium study that also opacifies on cholangiography was suggestive of a choledochocele.

On endoscopic gastroduodenoscopy, the papilla is always found proximal to a duodenal duplication cyst and distal to a choledochocele. ${ }^{13}$ But in type B choledochocele, the ampulla drains directly into the duodenum, with the cyst communicating only with the distal CBD; the papilla is also proximal to the choledochocele. We found that the papilla was proximal to the cyst in this case, suggesting a type B choledochocele.

Many articles claimed that the biopsy should be the gold standard for diagnosing choledochocele and duodenal duplication. Wada et al $^{13}$ thought that biopsy specimens inside the lesions reveal duodenal mucosa in all duodenal duplication cysts and bile duct mucosa in all choledochoceles. But duodenal-type mucosa on histology has been reported in choledochocele. ${ }^{14-16}$ Histological findings with choledochocele reported by Sarris and Tsang revealed duodenal-type mucosa in 15 , bile duct-type mucosa in 5, and untypical mucosa in 4 patients. ${ }^{11}$ In our case, the biopsy specimens revealed untypical duodenal mucosa with smooth muscle layer. This suggests that mucosal histology should not determine classification. There is no report of duodenal duplication with bile duct mucosa; the characteristic feature of a duplication cyst was two duodenal mucosal layers (with their respective muscularis mucosae), separated by a layer of submucosa. ${ }^{17}$ Therefore, if biopsy specimens inside the lesions reveal bile duct mucosa, choledochoceles can be diagnosed; if biopsy specimens inside the lesions reveal duodenal mucosa, radiologic criteria and anatomic features should be considered to make diagnosis.

\section{Conclusion}

This case highlights the difficulty of distinguishing between choledochoceles and duodenal duplication cysts preoperatively.
We considered that three diagnostic criteria must be met for a choledochocele to be diagnosed: (1) a cyst protruding into the duodenal lumen (confirmed by MRCP); (2) filling with contrast during cholangiography; and (3) filling defect on X-ray barium meal.

\section{Conflict Of Interest \\ None.}

\section{References}

1 Todani T, Watanabe Y, Narusue M, Tabuchi K, Okajima K. Congenital bile duct cysts: Classification, operative procedures, and review of thirty-seven cases including cancer arising from choledochal cyst. Am J Surg 1977;134(2):263-269

2 Yamaguchi M. Congenital choledochal cyst. Analysis of 1,433 patients in the Japanese literature. Am J Surg 1980;140(5):653-657

3 Ozel A, Uysal E, Tufaner O, Erturk SM, Yalcin M, Basak M. Duodenal duplication cyst: a rare cause of acute pancreatitis in children. J Clin Ultrasound 2008;36(9):584-586

4 Hata H, Hiraoka N, Ojima H, Shimada K, Kosuge T, Shimoda T. Carcinoid tumor arising in a duplication cyst of the duodenum. Pathol Int 2006;56(5):272-278

5 Cauchi JA, Buick RG. Duodenal duplication cyst: beware of the lesser sac collection. Pediatr Surg Int 2006;22(5):456-458

6 Yamauchi Y, Hoshino S, Yamashita Y, Funamoto S, Ishida K, Shirakusa T. Successful resection of an infected duodenal duplication cyst after percutaneous cyst drainage: report of a case. Surg Today 2005;35(7):586-589

7 Jo YC, Joo KR, Kim DH, et al. Duodenal duplicated cyst manifested by acute pancreatitis and obstructive jaundice in an elderly man. J Korean Med Sci 2004;19(4):604-607

8 Keller MS, Weber TR, Sotelo-Avila C, Brink DS, Luisiri A. Duodenal duplication cysts: A rare cause of acute pancreatitis in children. Surgery 2001;130(1):112-115

9 Prasad TR, Tan CE. Duodenal duplication cyst communicating with an aberrant pancreatic duct. Pediatr Surg Int 2005;21(4): 320-322

10 Koffie RM, Lee S, Perez-Atayde A, Mooney DP. Periampullary duodenal duplication cyst masquerading as a choledochocele. Pediatr Surg Int 2012;28(10):1035-1039

11 Sarris GE, Tsang D. Choledochocele: case report, literature review, and a proposed classification. Surgery 1989;105(3):408-414

12 Law R, Topazian M. Diagnosis and treatment of choledochoceles. Clin Gastroenterol Hepatol 2014;12(2):196-203 
13 Wada S, Higashizawa T, Tamada K, et al. Endoscopic partial resection of a duodenal duplication cyst. Endoscopy 2001;33(9):808-810

14 Ghazi A, Slone E. Endoscopic management of choledochocele. A case report and review of the English literature. Surg Endosc 1987; 1(3):151-154

15 Schimpl G, Sauer H, Goriupp U, Becker H. Choledochocele: importance of histological evaluation. J Pediatr Surg 1993;28(12):1562-1565
16 Lakhtakia S, Gupta R, Mateen MA, Lingareddy S, Rao GV, Reddy DN. Giant choledochocele presenting as intussusception (with video). Gastrointest Endosc 2008;68(6):1194-1195, discussion 1196

17 Antaki F, Tringali A, Deprez P, et al. A case series of symptomatic intraluminal duodenal duplication cysts: presentation, endoscopic therapy, and long-term outcome (with video). Gastrointest Endosc 2008;67(1):163-168 